\title{
Guarda compartilhada: princípio do melhor interesse da criança e do adolescente como norteador das decisões de guarda
}

Shared guard: principle of the best interests of children and adolescents as a guide for custody decisions

Custodia compartida: principio del interés superior de la niñez y la adolescencia como guía para las decisiones de custodia

\section{Resumo}

Este trabalho visa estudar a guarda compartilhada frente ao princípio do melhor interesse da criança e do adolescente à luz da legislação e jurisprudência. Através de um estudo sobre o poder familiar e da guarda compartilhada em si. Ressalta-se as inúmeras consequências da quebra do vínculo matrimonial, sobretudo na vida dos filhos. Com a evolução global nas últimas décadas, revolução sexual e questionamento do fundamentalismo religioso, a guarda dos filhos tornou-se problema crônico da sociedade capitalista. Assim, este trabalho objetiva estudar a relação entre guarda compartilhada e o princípio do melhor interesse da criança e do adolescente, demonstrando importância eefeitos da mesma em relação aos filhos após rompimento do vínculo conjugal. Ante o exposto, evidenciou-se a necessidade de observar as grandes modificações ocorridas na sociedade, sendo elas culturais, socio-econômicas, políticas e de preferência nas famílias e relações entre pais e filhos, destacando-se um grande aumento de rupturas de laços conjugais. Optou-se por uma pesquisa qualitativa de caráter bibliográfico e documental, buscando-se em bases eletrônicas de dados, artigos científicos e revistas, sendo a principal a Scientific Eletronic Library online (ScieLo). Por fim, considerando o princípio do melhor interesse da criança e do adolescente, tem-se que a guarda compartilhada, ao propiciar uma maior convivência familiar, assim como uma eficaz participação de ambos os pais na educação de sua prole, fatores imprescindíveis para preservação do bemestar emocional dos infantes, revela-se como modelo que leva à efetivação do princípio do melhor interesse da criança e do adolescente.

Palavras-chave: Guarda compartilhada; Princípio do melhor interesse da criança e do adolescente; Ponderação.

\begin{abstract}
This work aims to study shared custody in light of the principle of the best interests of children and adolescents in light of legislation and jurisprudence. Through a study of family power and shared custody itself. The countless consequences of breaking the marriage bond, especially in the lives of children, are highlighted. With global evolution in recent decades, sexual revolution and questioning of religious fundamentalism, child custody has become a chronic problem in capitalist society. Thus, this work aims to study the relationship between shared custody and the principle of the best interests of children and adolescents, demonstrating its importance and effects in relation to children after the marital bond is broken. In view of the above, the need to observe the major changes that have taken place in society was evidenced, which were cultural, socioeconomic, political and about preferences in families and relationships between parents and children, highlighting a large increase in the rupture of marital ties - A qualitative bibliographic and documentary research was chosen, searching electronic databases, scientific articles and journals, the main one being the Scientific Electronic Library online (ScieLo). Finally, considering the principle of the best interests of children and adolescents, shared custody, by providing greater family coexistence, as well as an effective participation of both parents in the education of their offspring, are essential factors for the preservation of the infants' emotional well-being, reveals itself as a model that leads to the realization of the principle of the best interests of children and adolescents.
\end{abstract}

Keywords: Shared guard; Principle of the best interests of children and adolescents; Weighting. 


\begin{abstract}
Resumen
Este trabajo tiene como objetivo estudiar la custodia compartida a la luz del principio del interés superior de la niñez y la adolescencia a la luz de la legislación y la jurisprudencia. Mediante un estudio del poder familiar y la propia custodia compartida. Enfatiza las numerosas consecuencias de romper el vínculo matrimonial, especialmente en la vida de los niños. Con la evolución global en las últimas décadas, la revolución sexual y el cuestionamiento del fundamentalismo religioso, la custodia de los hijos se ha convertido en un problema crónico en la sociedad capitalista. Así, este trabajo tiene como objetivo estudiar la relación entre la custodia compartida y el principio del interés superior de la niñez y la adolescencia, demostrando su importancia y efectos en relación a la niñez tras la ruptura del vínculo matrimonial. En vista de lo anterior, se evidenció la necesidad de observar los grandes cambios que se han producido en la sociedad, los cuales fueron culturales, socioeconómicos, políticos y preferentemente en las familias y las relaciones entre padres e hijos, destacando un gran incremento en las rupturas de los lazos matrimoniales. Se eligió una investigación bibliográfica y documental cualitativa, buscando en bases de datos electrónicas, artículos científicos y revistas, siendo la principal la Scientific Eletronic Library online (ScieLo). Finalmente, considerar el principio del interés superior de la niñez y la adolescencia, la custodia compartida, al brindar una mayor convivencia familiar, así como una participación efectiva de ambos progenitores en la educación de sus hijos, son factores fundamentales para la preservación del estado emocional de los infantes. bienestar, se revela como un modelo que conduce a la realización del principio del interés superior de la niñez y la adolescencia.

Palabras clave: Guardia compartida; Principio del interés superior de la niñez y la adolescencia; Ponderación.
\end{abstract}

\title{
1. Introdução
}

O presente trabalho tem como tema principal a aplicabilidade da guarda compartilhadafrente ao princípio do melhor interesse da criança, pois é de grande relevância porque tem sido bastante discutido em face das novas configurações familiares, e é cada vez mais frequente no cenário globalizado. Ressalta-se que são inúmeras as consequências dessa quebra de vínculo matrimonial, sobretudo com reflexos na vida dos filhos. Com a evolução da humanidade nas últimas décadas, a revolução sexual e o questionamento do fundamentalismo religioso, a guarda dos filhos tornou -se um problema crônico da sociedade capitalista.

Sabe-se que nos tempos de hoje o ato do divórcio se tornou algo comum, porem na maioria das vezes este ato não procede de forma pacífica, ainda mais quando não só os bens materiais, mas também os filhos estão em jogo. Para estes fins existem leis que colaboram para que esse processo seja o mais seguro possível. A guarda dos filhos, na grande maioriados casos é o assunto mais discutido nessas situações, onde os divorciados discutem com quem a criança irá ficar e quais as condições que serão estabelecidas na relação entre ambos. Antigamente, o regime da guarda dos filhos preferencial era de forma unilateral, onde apenas um dos genitores tinha o direito de permanecer com a criança e consequentemente ter o total domínio sobre as decisões futuras do filho(a), não podendo ter a interferência do ex parceiro(a), outro ponto específico dessa lei, era que na maioria das decisões a mãe era a principal responsável pela guarda da criança, ficando muito restrito a presença do pai na vida do mesmo.

Então, novos mecanismos de proteção à pessoa dos filhos foram estabelecidos. A convenção Internacional sobre os Direitos da criança de 1989, no Direito brasileiro em 1990, preconizou a proteção especial mediante o princípio do melhor interesse. De objeto de direto, a criança passou a sujeito de direitos. Logo a guarda compartilhada surge como instrumento de concretização dos princípios da melhor importância da criança e da igualdade de gêneros na sociedade conjugal.

Ainda neste sentido, o ECA postula, em seu artigo 22, que "aos pais incumbe o dever de sustento, guarda e educação dos filhos menores, cabendo-lhes ainda, no interesse destes, a obrigação de cumprir e fazer cumprir as determinações judiciais". Simultaneamente, pretende-se compreender a relação da guarda compartilhada com o dever da família em assegurar com absoluta prioridade a efetivação dos direitos referentes à vida, à saúde, à alimentação, ao esporte, ao lazer, à profissionalização, à cultura, à dignidade, ao respeito e à liberdade, conforme artigo $4^{\circ}$ do ECA.

A guarda compartilhada foi instituída pela lei 11.968, de 13 de junho de 2008, que alterou os artigos 1.853 e 1.854 do Código Civil, em 2014 o legislador aprovou a Lei 13.058, lei da guarda compartilhada que tem como seu maior objetivo a igualdade na tomada de decisões em relação ao filho, com o intuito de tentar preservar ao máximo os direitos edeveres relativos à 
autoridade parental.

Nesse cenário é que se levanta a questão problemática desta pesquisa: considerando o princípio do melhor interesse da criança e objetivando garantir a convivência familiar, a guarda compartilhada é a melhor modalidade de guarda que deve ser aplicada?

Assim, o presente trabalho terá como objetivo estudar a relação entre a guarda compartilhada e o princípio do melhor interesse da criança e do adolescente, demonstrando sua importância e os efeitos da mesma em relação aos filhos após o rompimento de um vínculo conjugal.

O trabalho se dividiu em quatro capítulos, sendo o primeiro a introdução, na qual descreve a finalidade do artigo, a problemática, seus objetivos e brevemente os métodos de pesquisa. O segundo capítulo vem para definir e conceituar a metodologia empregada na pequisa. O terceiro capítulo trata dos resultados obtidos e discute os mesmos, analisando o poder familiar, direitos e deveres dos pais no ordenamento jurídico, ao passo em que apresenta a aplicabilidade do princípio do melhor interesse da criança e do adolescente como norteador do poder familiar.Ainda, cuida-se da definição, modalidades e características de guardas, assim como, situações excepcionais da guarda compartilhada, e, por último, o quarto capítulo apresentando a conclusão do artigo, bem como seu entendimento acerca do assunto.

Neste aspecto, o presente estudo, enquanto técnicas de pesquisa fez uso da pesquisa com abordagem qualitativa, por meio de revisão bibliográfica e análise documental, consistente no estudo de doutrinas, artigos científicos, trabalhos monográficos e dissertativos básicos e especializados, e de áreas afins, e da pesquisa documental destinada à abordagem da guarda compartilhada frente ao princípio do melhor interesse da criança e do adolescente.

\section{Metodologia}

Esta pesquisa trata-se de uma revisão bibliográfica e documental, de caráter exploratório. Gil (2008, p. 27) conceitua que "as pesquisas exploratórias têm como principal finalidade desenvolver, esclarecer e modificar conceitos e ideias, tendo em vista a formulação de problemas mais precisos ou hipóteses pesquisáveis". Diante disso, o trabalho aqui efetuado se deu por meio de pesquisa exploratória quanto aos objetivos, a fim de se alcançar a compreensão do tema "guarda compartilhada frente ao princípio do melhor interesse da criança e do adolescente sob a luz da legislação e jurisprudência”, o qual foi explorado por meio de procedimento técnico bibliográfico.

Segundo Gil (2008, p. 27) a pesquisa bibliográfica "é desenvolvida a partir de material já elaborado, constituído principalmente de livros e artigos científicos". O método bibliográfico foi aqui usado na construção do referencial teórico, a fim de expor conceitos e todo o aspecto teórico envolvendo o tratamento das informações e dados colhidos.

Quanto ao método de abordagem, optou-se pelo método indutivo, que segundo Gil (2008, p. 10) "procede inversamente ao dedutivo: parte do particular e coloca a generalização como um produto posterior do trabalho de coleta de dados particulares". Utilizando o método indutivo, a pesquisa foi desenvolvida analisando-se a legislação e a jurisprudência brasileira concernente ao intituto da guarda compartilhada.

No que tange à abordagem, optou-se pela abordagem qualitativa, uma vez que, por meio desta, foi possível adquirir uma visão ampla de como tal instituto está inserido no ordenamento pátrio. Como colocam Prodanov e Freitas (2013, p. 70) "na pesquisa qualitativa, os pesquisadores tendem a analisar seus dados indutivamente. O processo e seu significado são os focos principais de abordagem". O método de abordagem qualitativo foi, portanto, ideal à construção da pesquisa. Na revisão de literatura buscaram-se meios de pesquisa em bases eletrônicas de dados tais como: artigos científicos, revistas, sendo a principal Scientific Eletronic Library online (ScieLo). 


\section{Resultados e Discussão}

\section{1 poder familiar, direitos e deveres dos pais no ordenamento jurídico brasileiro}

No ano de 2002 foi aprovado o Código Civil, que procurou-se adaptar à realidade da totalidade social, em que os vínculos afetivos se acrescentam aos vínculos biológicos esanguíneos, dando lugar para o tratamento igualitário dos filhos, a afetividade, e a responsabilidade ligada dos progenitores no exercício do poder familiar. O autor Gonçalves (2010) esclarece que as inovações originadas pela Constituição de 1988 e pelo Código Civil de 2002, oferecem uma visão panorâmica das intensas alterações requeridas no direito de família do Brasil, evidenciando a função social da família, ao observar a igualdade entre cônjuges e determinar uma base na família, pois, com a queda do patriarcalismo a obrigação de zelar pela família deixou de ser um dever somente do pai, sendo então uma obrigação comum dos cônjuges.

O Estatuto da Criança e do Adolescente (ECA) veio reforçar essa modificação de modelo. Em seu texto inicial determinava que:

O pátrio poder será exercido, em igualdade de condições, pelo pai e pela mãe, na forma do que dispuser a legislação civil, assegurado a qualquer deles o direito de,em caso de discordância, recorrer à autoridade judiciária competente para a solução das divergências (Lei n. 8.069, 1990).

Contudo, no ano de 2009, sofreu modificação em seu texto, através da Lei 12.010, passando a incluir-se da seguinte maneira:

Art. 21. O pátrio poder, poder familiar será exercido, em igualdade de condições, pelo pai e pela mãe, na forma do que dispuser a legislação civil, assegurado a qualquer deles o direito de, em caso de discordância, recorrer à autoridade judiciária competente para a solução da divergência (Lei n. 12.010, 2009).

Já no Código Civil, em seu art. 1631 está escrito da seguinte maneira: “durante o casamento e a união estável, compete o poder familiar aos pais; na falta ou impedimento de um deles, o outro o exercerá com exclusividade” (Lei n. 10.406, 2002).

Também traz em seu artigo 1.632, a seguinte forma cerca da separação do casal: “A separação judicial, o divórcio e a dissolução da união estável não alteram as relações entre pais e filhos senão quanto ao direito, que aos primeiros cabe, de terem em sua companhia os segundos” (Lei n. 10.406, 2002). Mesmo depois a separação, a lei assegura aos pais a sustentação de seu poder familiar sobre os filhos, precisando acontecer somente uma decisão sobre qual será o melhor regime de visitação E convivência aos filhos, buscando sempre princípio basilardo ECA, o melhor interesse da criança.

O fato é que as separações de casais são muito mais reiteradas na atualidade, procedendo quase consecutivamente em litígios, tanto de caráter patrimonial quanto afetiva, decompondo sobremaneira o exercício do poder familiar e da relação parental. De acordo com o que relata Maria Berenice Dias:

Podem aparecer na criança sob forma de ansiedade, medo e insegurança, isolamento, tristeza e depressão, comportamento hostil, falta de organização, dificuldades escolares, baixa tolerância à frustração, irritabilidade, enurese, transtorno de identidade ou de imagem, sentimento de desespero, culpa, dupla personalidade, inclinação ao álcool e às drogas (Dias, 2010, p. 98).

A Carta Magna de 1988 igualou os direitos e deveres dos cônjuges, através do art. 226, $\S 5^{\circ}$, em que estabelece que “Os direitos e deveres referentes à sociedade conjugal são exercidos igualmente pelo homem e pela mulher” (Constituição, 1988). Com o desenvolvimento das relações sociais, a família foi aos poucos perdendo seu costume intensamente patriarcal, com uma hierarquia bem determinada, dando lugar a relações mais horizontalizadas. Ao abafar seu objetivo puramente 
reprodutivo e patrimonial, dando lugar à formação da família por conta dos vínculos afetivos, a figura máscula, como administrador de família responsável pelo mantimento de todos os seus membros perdeu o conceito.

A inclusão da mulher no negócio de trabalho acarretou profundas alterações nasrelações familiares, colocando-a em igualdade com o "patriarca", começando mãe e pai a ser corresponsáveis pela tomada de decisão e por abastecer o sustento da família.

A autora Maria Berenice Dias (2010) assegura que a Constituição Federal de 1988, realizou a grande reforma já sucedida no direito de família, ao garantir, já em seu preâmbulo,o direito à igualdade e objetiva ao Estado requerer o bem de todos, sem preconceito de sexo.A avaliação de família foi vastamente modificada, ganhando um tratamento mais igualitário e abrangente.

Já, de acordo com Carlos Roberto Gonçalves (2016) as alterações sociais tornaram o Código Civil de 1916 antiquado nos pontos referentes ao direito de família, fazendo com que diversos de seus dispositivos restassem revogados, trazendo a obrigação da elaboração de um novo Código Civil, que procurasse disciplinar todas as novidades acarretadas pela nova Constituição de 1988.

Existe o contexto da família monoparental, da união homoafetiva e tantas outras, e compete ao Direito se adaptar à nova realidade social. Contudo essa adaptação tem caráter multidisciplinar, não competindo apenas às ciências jurídicas perceber esses novos acontecimentos sociais de modo independente, necessitando se proteger na psicologia, na sociologia, e diferentes áreas de conhecimento para que o ordenamento jurídico seja apropriado para solucionar, de modo eficaz, os problemas emergentes e urgentes.

\subsection{Princípio do melhor interesse da criança e do adolescente como norteador do poder familiar}

O ensinamento acerca da proteção integral da criança e do adolescente nasceu na Convenção Internacional sobre os Direitos da Criança de 1989, e fez com que crianças e adolescentes virassem sujeitos de direito e por permanecerem em desenvolvimento e serem indefesos e vulneráveis, de alguma ação, seja da sociedade, do Estado ou de seus genitores, precisa ser voltada a protege-los e resguardar seus direitos com absoluta prioridade.

O princípio do melhor interesse da criança é resguardado no art. 227 da Carta Magna, qual tem suas ascendências na Declaração Universal dos Direitos da Criança seguida pela ONU em 1959, e tem como objetivo resguardar a proteção especial, serviços e oportunidades que permitam o desenvolvimento físico, moral, mental e social de maneira normal e saudável, assim como condições de dignidade e liberdade para as crianças. Contudo, não tem uma definição concisa do que seja o melhor interesse da criança e do adolescente que é primeiramente estabelecido pelo juiz em caso concreto.

Na Constituição Federal de 1988, este princípio está estabelecido no art. 227, veja-se:

Art. 227. É dever da família, da sociedade e do Estado assegurar à criança, ao adolescente e ao jovem, com absoluta prioridade, o direito à vida, à saúde, à alimentação, à educação, ao lazer, à profissionalização, à cultura, à dignidade, ao respeito, à liberdade e à convivência familiar e comunitária, além de colocá-los a salvo de toda forma de negligência, discriminação, exploração, violência, crueldadee opressão (Constituição, 1988).

Por diversas vezes, tem que se confrontar com casos fáticos que dirigirão os aplicadores do direito a preferirem por soluções que simulem o menos lesivo para a criança e para o adolescente.

Nas doutrinas, é revelado da seguinte maneira conforme Eduardo Leite:

O interesse do menor serve, primeiramente, de critério de controle, isto é, de instrumento que permite vigiar o exercício da autoridade parental sem questionar a existência dos direitos dos pais. Assim, na família unida, o interesse presumido da criança é de ser educado por seus dois pais, mas se um deles abusa ou usa indevidamente suas 
prerrogativas, o mesmo critério permitirá lhe retirar, ou controlar mais de perto, o exercício daquele direito. O interesse do menor é utilizado, de outro lado, como critério de solução, no sentido de que, em caso de divórcio, por exemplo, a atribuição da autoridade parental e do exercício de suas prerrogativas pelos pais depende da apreciação feita pelo juiz do interesse do menor (Leite, 2003, p. 97).

Assim sendo, o poder judiciário nas ações de guarda tem como prioridade o melhor interesse da criança e do adolescente precisando basear suas decisões de maneira que assegure a proteção especial do menor. O princípio do melhor interesse da criança e do adolescente situou o menor ao núcleo do debate jurídico em se falando de guarda, analisando-se antes do interesse dos progenitores o interesse maior do menor. Portanto, tem a prioridade dos direitos dos filhos na esfera administrativa, extrajudicial, judicial, familiar e social.

A guarda compartilhada tem como finalidade querer as reais necessidades dos menores. A primazia é o bem-estar dos menores, colocando em segundo plano os interesses dos genitores. Considerando suas características, cada caso concreto precisará ser colocadoem específico exame, considerando as particularidades dos núcleos familiares para a opção daguarda, sempre priorizando o princípio do melhor interesse da criança e do adolescente para a aquisição das basilares condições para o completo desenvolvimento dos filhos.

Os direitos da proteção integral estão revelados tanto na Constituição Federal de 1988, quanto no Estatuto da Criança e Adolescente, tendo em vista tamanho importância desta teoria, a qual cumpre uma função estruturante na sociedade no grau em que reconhece todos os direitos essenciais à pessoa humana, assim como os direitos resultantes da condição característica de pessoa em desenvolvimento.

Desse modo, o princípio do melhor interesse da criança e do adolescente deve ser percebido como o baseamento principal de todas as ações relacionadas aos menores, sendo que, qualquer decisão ou orientação associada à vida das crianças e adolescentes precisa levar em consideração o que é mais adequado e melhor para satisfazer seus interesses e suas necessidades, sobrepondo-se até mesmo aos interesses dos genitores, almejando de tal modo, a proteção integral dos seus direitos.

Os benefícios do modelo precisam superar qualquer conflito pessoal entre os pais mesmo que se faça imprescindível a assistência de profissionais. De tal modo, precisa-se levar em consideração a necessidade de constatar o indivíduo com quem a criança, principalmente aqueles de tenra idade, sustenta laços mais fortes de carinho e afetividade, como resultado de atendimento habitual às suas necessidades psicológicas e biofísicas (Machado, 2003).

Deste modo, o melhor interesse a criança e o adolescente relaciona-se não apenas em determinar com quem ficará a guarda, contudo, além disso, em se preocupar com todos as características e atributos que envolvem seu bom desenvolvimento e o bem-estar do menor.

O princípio do melhor interesse da criança e do adolescente, tem-se que a guarda compartilhada, ao propiciar uma maior convivência familiar, assim como uma eficaz participação de ambos os pais na educação de sua prole, fatores imprescindível para a preservação do bem-estar emocional dos infantes, revela-se como o modelo que leva à efetivação do princípio do melhor interesse da criança e do adolescente.

O princípio do melhor interesse da criança objetiva a proteção de pessoas incapazes, bem como de suas propriedades. Também de acordo com Pereira (2008), a realização e consolidação deste princípio no sistema jurídico brasileiro devem-se aos princípios seguidos por este sistema e aos tratados do qual ele faz parte.

$\mathrm{O}$ melhor interesse da criança possui status de princípio constitucional e merece ser ponderado junto aos outros princípios constitucionais, pois, conforme Pereira (2008), é um princípio de suma importância no ordenamento jurídico pátrio e um dos pilares do Direito da criança e do adolescente.

Dessa forma, esse princípio nasceu com o intuito de garantir os direitos inerentes ao menor, como uma cláusula 
genérica que inspira os direitos fundamentais assegurados pela Constituição às crianças e adolescentes. E como afirma Paulo Lôbo (2011, p. 45) "o princípio não é uma recomendação ética, mas diretriz determinante nas relações dos menores com seus pais, com a sociedade e com o Estado."

\subsection{Guarda compartilhada}

O tema em análise é pouco explorado por doutrinadores, a guarda compartilhada no Brasil veio com advento da Lei 11.698 em junho de 2008, apesar de ter origem na Roma Antiga, mas se consolidou de fato nos Países Europeus como Inglaterra, França, Alemanha, Portugal, bem como no Canadá e Estados Unidos no início do século XX.

A guarda compartilhada foi instituída pela lei 11.698, de 13 de junho de 2008, que alterou os artigos 1.853 e 1.854 do Código Civil, em 2014 o legislador aprovou a Lei 13.058, lei da guarda compartilhada que tem como seu maior objetivo a igualdade na tomada de decisões em relação ao filho, com o intuito de tentar preservar ao máximo os direitos e deveres relativos à autoridade parental. Segundo Flávio Tartuce (2015) a guarda compartilhada passou a ser, espécie obrigatória ou compulsória.

Tartuce (2015) vai além e explica que o entendimento pela obrigatoriedade se dá visto que, mesmo quando presentes argumentos de um dos genitores declinado a opção pela guarda compartilhada, o juiz poderá, compulsoriamente, deferir tal modalidade, sempre tendo em vista o princípio o melhor interesse da criança.

Com o passar dos anos, a preferência pela guarda da criança foi conferida à mãe. Posteriormente, a visão sobre a responsabilidade dos pais frente aos filhos foi sendo alterada, sendo que na atualidade, o direito inglês busca distribuir a responsabilidade, de forma igualitária, entre os genitores (Azambuja, 2007).

A palavra guarda vem das expressões alemã wargem (guarda, espera), do inglêswarden (guarda) e do francês garde, segundo De Plácido e Silva (1990), tendo o sentido mais simplificado e genérico o de proteção, observação, vigilância, segurança dos filhos, umdireito-dever recebido do Estado e da coletividade para os pais protegerem os filhos dos riscos e o acompanharem em seu crescimento, dando formação moral, mental e física, a ser desempenhada no interesse da prole. O seu atributo é o meio imprescindível para a concretização do poder familiar, dando cuidando de sua sobrevivência e desenvolvimento (Melo, 2014).

O Código Civil conceitua a guarda compartilhada como art. $1.583, \S 1^{\circ}$, segunda parte do Código Civil: "responsabilização conjunta e o exercício de direitos e deveres do pai e da mãe que não vivam sob o mesmo teto, concernentes ao poder familiar dos filhos comuns" (Lei n. 10.406, 2002).

Nas palavras de Flávio Tartuce (2015, p. 207), a guarda compartilhada ou guarda conjunta consiste em "hipótese em que pai e mãe dividem as atribuições relacionadas ao filho,que irá conviver com ambos, sendo essa sua grande vantagem".

Buscando incrementar os casos da guarda compartilhada, houve o advento da Lei $\mathrm{n}^{\circ} 13.058$ de 2014, reconhecida pela doutrina e pela sociedade em geral como a lei da obrigatoriedade da guarda compartilhada. Conforme revela Flavio Tartuce (2015), a lei em comento alterou o $\S 2^{\circ}$ do art. 1.584 do Código Civil, de modo que a redação atual prevê a obrigatoriedade da guarda compartilhada.

A finalidade da guarda compartilhada é possibilitar o convívio e vínculo afetivo dos pais e filhos mesmo com a ruptura conjugal. A criança necessita da presença dos pais para seubom desenvolvimento. A guarda compartilhada outorga eficácia a princípios constitucionais como o melhor interesse da criança, igualdade entre os cônjuges e convivência familiar, sendonecessário para amenizar os efeitos negativos que a separação do casal pode operar sobre a criança.

\subsection{Outras modalidades de guarda no ordenamento jurídico brasileiro}

Os benefícios da guarda compartilhada são enormes, e dentre eles pode-se elencar: convivência com ambos os pais; 
preservação da parentalidade compartilhada; igual responsabilidade dos pais em relação ao filho; os efeitos da separação dos pais é minimizado; possibilidade de exercício da plenitude do poder familiar; as tarefas dos pais em relação ao filho normalmente continuam sendo as mesmas de antes da separação; melhor saúde mental das crianças; constante comunicação sem horários rígidos; redução das possibilidades de problemas emocionais ou de baixa autoestima (Lôbo, 2011).

\subsubsection{Unilateral}

Nesta modalidade, a guarda é imposta a um só genitor, aquele que de acordo com o código civil, estabelecido no artigo 1583, § $2^{\circ}$ que apareça melhores condições de desempenhar e, objetivamente, tenha competência para propiciar ao filho afeto, saúde, segurança e educação, sendo que o outro adota um regime de visitação e prestação dealimento, assim como o direito de supervisionar as decisões tomadas, e, se imprescindível pode procurar auxílio do poder judiciário para resolver assuntos para melhor interesse do menor.

A guarda unilateral é desempenhada por somente um dos genitores, desagradando somente a um dos genitores, conforme artigo 1.584 , parágrafo $1^{\circ}$ do Código Civil (Lei n. 10.406, 2002). Na maior parte dos casos a guarda do filho era conferida à mãe que captava a guarda física, pelo convívio cotidiano com o filho e além disso a guarda jurídica, restando ao pai o direito de visita e vigilância.

Este foi sempre o modelo mais comum e mais aproveitado no Brasil, contudo, mesmo tão invadida, com o passar do tempo ela foi sendo bastante criticada oferecida a concepção de igualdade entre os genitores e, especialmente, o melhor interesse da criança, podendo aguarda até mesmo ser deferida a terceiro.

\subsubsection{Aninhamento}

A guarda por aninhamento ou nidação é um caso raro, onde os pais se mudam para a casa do filho em periodicidade alternada, o filho mora e continua em uma só casa e com os mesmos costumes.

\subsubsection{Alternada}

Na alternada os pais não se mudam para a mesma casa de tempos em tempos, entretanto são os filhos que alternam sua moradia entre as casas de seus genitores. Este modelo ainda é pouco recomendável, visto que configura uma circunstância que se mostra como irreal, por isso pouco empregada, além de trazer a mesma descontinuidade familiar quea guarda mencionada antes (Nader, 2013).

De acordo com Diniz, caracteriza a guarda alternada da seguinte maneira:

A guarda alternada caracteriza-se pela possibilidade de cada um dos pais deter a guarda do filho alternadamente, segundo um ritmo de tempo que pode ser um ano escolar, um mês, uma semana, uma parte da semana, ou uma repartição organizada dia a dia e, consequentemente, durante esse período de tempo deter, de forma exclusiva, a totalidade dos poderes-deveres que integram o poder paternal (Diniz, 2015, p.27).

No término do período, os papéis invertem-se. É um tipo de guarda em que se tem a atribuição da guarda física e legal alternamente a cada um dos pais, de forma que ao passoque a um está o período de guarda, ao outro só cabe o direito de visita, se transferindo as posições conforme os períodos estabelecidos, independentemente de manifestação judicial.

\subsubsection{Compartilhada}

Os benefícios da guarda compartilhada, reside na possibilidade de ambos os genitores, em conjunto, tomarem decisões importantes quanto ao bem-estar, educação e criação do menor. Privilegia desta forma, a continuidade do exercício comum da autoridade parental. 
O termo guarda compartilhada ou guarda conjunta de menores refere-se à possibilidade de os filhos serem assistidos por ambos os pais. Nela, os pais têm efetiva e equivalente autoridade legal para tomar decisões importantes quanto ao bem-estar de seus filhos e frequentemente têm uma paridade maior no cuidado a eles do que os pais com guardaúnica.

Segundo o art. 1.583, $\S 1^{\circ}$, do Código Civil Brasileiro, a guarda compartilhada é "a responsabilização conjunta e o exercício de direitos e deveres do pai e da mãe que não vivam sob o mesmo teto, concernentes ao poder familiar dos filhos comuns" (Lei n. 10.406, 2002).

\subsection{Guarda compartilhada como garantidora do melhor interesse da criança e do adolescente}

A Lei n ${ }^{\circ} 13.058$ procurou fortalecer o instituto da guarda compartilhada de modo que está guarda seja adotada não só em situações em que os pais estejam em completa harmonia, mas também em casos em que estes não concordem plenamente. É claro que cabe ao juiz analisar se o caso concreto possibilita a adesão ao compartilhamento da guarda, posto que é necessário que os pais, para levar a cabo essa modalidade de guarda, decidam sobre assuntos importantes da vida dos filhos em consonância.

Desse modo, decidir sobre a escola, a atividade esportiva, experiências de lazer passa aser tarefa de ambos os pais e não de apenas um deles, que devem exercer esse múnus sempre pensando no melhor para seu filho (Venosa, 2013).

O artigo 33 do Estatuto da Criança e do Adolescente define a guarda como "a obrigação à prestação material, moral e educacional à criança ou adolescente, conferido aoseu detentor" para que estes se desenvolvam de modo saudável (Lei n. $8.069,1990)$.

Para atender melhor aos interesses e necessidades dos filhos de pais separados, visando o equilíbrio dos papéis paternos, surgiu no ordenamento jurídico a guarda compartilhada, aquela em que ambos os pais possuem a guarda, em conjunto (Carvalho, 2015). Os dois, de forma coordenada, harmônica e efetiva participam do desenvolvimento da criança, dividindo as responsabilidades e possuindo direitos e deveres relacionados aos filhos, decidindo juntos os assuntos relacionados a eles, o que possibilita uma relação mais próxima entre pais e filhos, da forma como era, antes da separação.

Passando a separação apenas entre os pais e não entre os pais e estes, possibilitando assim, uma maior integração e uma participação ativa na criação dos filhos. Para Leite(2003) o melhor interesse da criança e do adolescente está ligado às práticas que refletem no bom desenvolvimento moral, social, psicológico, emocional etc.

E nada obsta a que se decida pela guarda compartilhada, forma de custódia em que, como ensina Gonçalves (2016), os filhos têm uma residência principal, mas os pais têm responsabilidade legal sobre eles, ambos os genitores, tendo o outro o direito de visitá-lo periodicamente, mas a responsabilidade legal sobre o filho e pela sua educação seria bilateral, ou seja, do pai e da mãe. O poder familiar seria exercido por ambos, que tomarão conjuntamente as decisões no dia-a-dia.

Nesta modalidade de guarda é assegurado aos menores o direito de ter seus pais em sua companhia e tendo obrigação em relação aqueles, a guarda compartilhada não pode ser uma ideia fechada e excludente da família, conforme Miguel Reale (1998) o princípio da sociabilidade não se confunde com socialismo. Para Reale um princípio leva ao outro, que é o da concretude, sendo a função social da família.

Vale lembrar que, depois do Código Civil de 2002, a maior idade passou de 21 para 18 anos. Dessa forma, no seu sentido mais amplo a guarda é o conjunto de deveres incumbidos do Estado e da coletividade para os pais com filhos menores, Maria Helena Diniz a define:

A guarda é um conjunto de relações jurídicas existente entre o genitor e o filho menor, decorrente do fato de estar sob o poder e companhia e de responsabilidade daquele relativamente a este, quanto à sua criação, educação e vigilância. A guarda éo poder- dever exercido no interesse do filho menor de obter boa formação moral, social e psicológica, saúde mental e preservação de sua estrutura emocional. (Diniz, 2015, p. 287). 
Carbonera (2000) também menciona que a guarda compartilhada possui relação com o princípio da igualdade, pois compete a ambos os genitores a divisão por igual de todas as responsabilidades e deveres inerentes a criação da criança. A criança não deve sofrer ou ser prejudicado por qualquer problema ou desentendimento que possa ocorrer pela quebra dessa relação conjugal, uma vez, que o que ocorreu foi a separação entre marido e mulher, e não da família parental, dessa forma continuam a exercer o papel de família, mas não a relação de casal, assim, o sentindo de família deve sempre ser resguardado, evitando maiores prejuízos.

Os pais podem acompanhar livremente a vida de sua prole. A participação dos pais na vida dos filhos, é como era quando casados. O que pode possibilitar a longo prazo, estabilidade e bom desenvolvimento da prole. Pois substitui o pai ou mãe de fim de semana, para pais sempre presentes diariamente na vida dos filhos, na tomada de decisões e participação igualitárias deles na tomada de decisões relativas ao desenvolvimento e ao bem- estar dos filhos, dentre outros, momentos que a prole necessita da presença constante dos seusgenitores na rotina diária (Buosi, 2012).

Em análise do que exatamente a lei pretende abordar como interesse do menor, se faz necessária a observância ao esclarecimento de Leite nesse ponto:

O interesse do menor serve, primeiramente, de critério de controle, isto é, de instrumento que permite vigiar o exercício da autoridade parental sem questionar a existência dos direitos dos pais. Assim, na família unida, o interesse presumido da criança é de ser educado por seus dois pais; mas se um deles abusa ou usa indevidamente suas prerrogativas, o mesmo critério o permitirá retirar, ou controlar mais de perto, o exercício daquele direito (Leite, 2003, p. 195).

O interesse do menor é utilizado, de outro lado, como critério de solução, no sentido de que, em caso de divórcio, por exemplo, a atribuição da autoridade parental e do exercício de suas prerrogativas pelos pais depende da apreciação feita pelo juiz do interesse do menor.

\subsection{Situações excepcionais em que a guarda compartilhada afronta o melhor interesse da criança e do adolescente}

A aplicação do princípio do melhor interesse da criança e do adolescente necessita ser ressaltada em cada caso de litígio acerca da guarda. Na realidade, se a criança ou o adolescente for satisfatoriamente madura, os tribunais precisam considerar a sua preferência. Contudo, essa manifestação volitiva da criança e do adolescente não é suficiente. A continuidade, estabilidade e a permanência na relação familiar precisam ser ainda priorizadas. Nas palavras de Pereira:

Identificamos o "melhor interesse da criança", nos dias de hoje, como uma norma cogente não só em razão da ratificação da Convenção da ONU (por meio do Decreto 99.710/90), mas também porque estamos diante de um princípio especial, o qual, a exemplo dos princípios gerais de direito, deve ser considerado fonte subsidiária na aplicação da norma (Pereira, 2008, p. 215).

Ressaltando ainda esses aspectos, o Tribunal de Justiça de Santa Catarina TJ-SC, aborda da seguinte maneira o bemestar da criança e do adolescente:

GUARDA DE FILHO. PRESERVAÇÃO DO INTERESSE DO MENOR. CONDIÇÕES DE AMBOS OS GENITORES. PRESERVAÇÃO DOS LAÇOS PATERNOS E MATERNOS. GUARDA COMPARTILHADA. Sendo um direito primordial da criança conviver pacificamente tanto com o pai quanto com a mãe, ainda quando sobrevém a separação do casal, tem-se a guarda compartilhada como um instrumento para garantir esta convivência familiar. É fundamental para um bom desenvolvimento social e psicológico que a criança possa conviver sem restrições com seus genitores, devendo a decisão a respeito da guarda de menores ficar atenta ao que melhor atenderá ao bem-estar dos filhos dos casais que estão a se separar. Assim, tendo as provas até o momento produzidas indicando que ambos os genitores possuem condições de ficar com o filho menor, tem-se que a melhor solução para o caso concreto é a aplicação da guarda compartilhada sem restrições (Brasil. Santa Catarina. Tribunal de Justiça de Santa 
Catarina. Agravo de Instrumento n. 2001.012993-0. Relator: Des. Carlos Prudêncio. Laguna, 25/03/2003).

Vale ressaltar que, pré-requisitos devem ser levados em consideração para adoção da guarda compartilhada entre eles está a categoria da criação dos filhos, por espantoso que semelhe, existe genitores sem condição, não somente financeira, porém psicologicamente de criarem seus filhos, então se os dois estiverem em empate de condições o juiz precisa adotar o padrão:

AGRAVO DE INSTRUMENTO - MEDIDA CAUTELAR DE SEPARAÇÃO DE CORPOS C/C GUARDA E ALIMENTOS - PEDIDO DE ASSISTÊNCIA JUDICIÁRIA GRATUITA INDEFERIDO - NECESSIDADE DEVIDAMENTE COMPROVADA - ADMISSIBILIDADE DE CONCESSÃO DA BENESSE - EXEGESE DO ART. $4^{\circ}$ DA LEI N. 1.060/50 - GUARDA COMPARTILHADA DEFERIDA - POSSIBILIDADE - PAIS EM IGUALDADE DE CONDIÇÕES - INTERESSE DOS MENORES QUE PREVALECE SOBRE QUALQUER OUTRO - FIXAÇÃO DA VERBA ALIMENTAR EM DEZESSEIS POR CENTO DOS RENDIMENTOS DO ALIMENTANTE - PEDIDO DE MAJORAÇÃO - ALEGAÇÃO DE QUE O AGRAVADO DESFRUTA DE CONFORTÁVEL SITUAÇÃO FINANCEIRA - AUSÊNCIA DE COMPROVAÇÃO - CRITÉRIO DE ARBITRAMENTO MANTIDO - RECURSO PARCIALMENTE PROVIDO. 1. Nos termos do art. $4^{\circ}$ da Lei $\mathrm{n}$. 1.060/50, com a redação que lhe conferiu a Lei n. 7.510/86, a parte gozará dos benefícios da assistência judiciária gratuita mediante simples afirmação, na própria petição, de que não tem condições de pagar as custas do processo sem prejuízo próprio ou de sua família. 2. Em se tratando de guarda, a escolha dos filhos é suprema em relação a outros fatores. Deste modo, possuindo ambos os pais condições de permanecer com a prole, a solução mais acertada é o deferimento da guarda compartilhada, ainda mais quando esta é a vontade dascrianças e os genitores não se opõem ao compartilhamento. 3. Em sede de agravo de instrumento, o exame das provas se limita apenas ao que foi apresentado pelas partes. Não se verificando qualquer irregularidade na decisão vergastada e nãocomprovando a agravante os fatos noticiados no recurso, o pleito recursal, porconseguinte, não pode ser acolhido (Brasil. Santa Catarina. Tribunal de Justiça de Santa Catarina. Agravo de Instrumento n. 2002.009848-0. Relator: Des. Mazoni Ferreira. Florianópolis, 03/10/2002).

Enquanto determinadas decisões referentes à guarda compartilhada levam emconsideração somente a harmonia entre os cônjuges, precisa-se advertir que o que verdadeiramente custa é a relação entre os progenitores e as crianças, evidentemente se os pais não tiverem conflito qualquer tanto melhor, porém coibir o menor da presença de um dos progenitores só porque os dois não conseguem resolver seus problemas é castigar a criança ouadolescente por uma briga que não lhe tem a ver.

\section{Considerações Finais}

Observando as grandes modificações ocorridas na sociedade, sendo elas culturais, sociais, econômicas, políticas e de preferência nas famílias e nas relações entre pais e filhos, destaca-se um grande aumento de rupturas de laços conjugais.

Desse modo o sentimento de término de família perpetuava, causando implicações emocionais negativas na criança, afetando também sua personalidade. Sem contar que essas implicações também se apresentavam na vida dos genitores, uma vez que, estavam vivendo em um ambiente cheio de rancor causado pela separação, frustração, decepção e culpa que arruinava uma ou ambas as partes.

A guarda compartilhada tem como intuito favorecer os interesses da criança e doadolescente e diminuir os abalos causados pela separação dos pais. Essa norma, buscaalcançar esse objetivo ao possibilitar o cumprimento dos direitos próprios à condição de pessoa em desenvolvimento, em particular a cooperação simultânea dos pais no seu cotidiano. $\mathrm{O}$ trabalho objetivou estudar a relação entre a guarda compartilhada e o princípio do melhor interesse da criança e do adolescente, demonstrando sua importância e os efeitos da mesma em relação aos filhos após o rompimento de um vínculo conjugal.

Demonstrou-se que mesmo em episódios de separação litigiosa a guarda compartilhada precisa ser aplicada ainda 
mesmo para diminuir o conflito entre os ex-cônjuges deixando de lado as aflições particulares entre os progenitores e abrangendo o relacionamentoentre os pais e os filhos. Até mesmo com o objetivo da igualdade assegurada pelo artigo $5^{\circ}$ da Carta Magna, a guarda compartilhada tem o papel de compensar todas as responsabilidades que não devem e não podem ser rejeitadas por nenhum dos pais.

Nesse sentido, é preciso o envolvimento de todos as partes da sociedade para alterar o real fato vivenciado pelas crianças e adolescentes que não podem mais permanecer à mercê decircunstâncias de negligência, violência e abandono que são transmitidas por meio das gerações.

A guarda compartilhada está regulamentada na Lei no 13.058 de 2014, que modificouo que estava estabelecido nos artigos do Código Civil de 2002, vem ser obrigatória a guarda compartilhada nos fatos em que não existirem empecilhos para a sua aplicação e estabelecimento que o tempo de convivência dos filhos seja dividido entre os genitores de maneira igual, considerando os interesses e as condições fáticas dos mesmos.

É imprescindível que os genitores deixem de lado seus próprios interesses, possíveis amarguras e problemas atuando de maneira cooperativa para o mais perfeito bem-estar dos filhos. Acerca disso, mesmo que a guarda compartilhada seja uma norma e a escolha de melhores benefícios por que se percebe que para um com desenvolvimento infantil, a criança e ao adolescente necessita de ambos os pais atuantes e presentes na sua vida, determinadas vezes o juiz escolhe por outro tipo de guarda para assegurar o melhor bem-estar do menor.

Embora a regra é a guarda compartilhada, diversas vezes não é uma alternativa para determinadas famílias onde os genitores passam por períodos de muitos desentendimentos onde o convívio frequente somente agravaria referente aos dois e o desenvolvimento da criança ou do adolescente em questão, que pode até mesmo ser vítima de alienação parental.

Por fim, conclui-se que se faz imperioso arrazoar acerca dos meios necessários para resolver a deficiência do Estado referente à proteção da criança e do adolescente, com a visão de que as garantias destes, não continuem somente no plano teórico, contudo que se apliquem de maneira efetiva.

\section{Referências}

Azambuja, M. R. F. (2007). A Criança vítima de violência sexual intrafamiliar: comooperacionalizar as visitas? In: M. B. Dias. (coord.). Incesto e alienação parental: realidades que a Justiça insiste em não ver (pp. 187-207). Revista dos Tribunais.

Constituição da República Federativa do Brasil de 1988. (1998). Brasília, DF. http://www.planalto.gov.br/ccivil_03/constituicao/constituicao.htm

Lei $n^{o}$ 8.069, de 13 de julho de 1990. (1990). Dispõe sobre o Estatuto da Criança e do Adolescente e dá outras providências. Brasília, DF. Recuperado de http://www.planalto.gov.br/ccivil_03/Leis/L8069.htm

Lei $n^{\circ}$ 10.406, de 10 de janeiro de 2002. (2002). Institui o Código Civil. Brasília, DF. http://www.planalto.gov.br/ccivil_03/leis/2002/110406.htm

Lei $n^{o}$ 12.010, de 3 de agosto de 2009. (2009). Dispõe sobre a adoção. Brasília, DF. http://www.planalto.gov.br/ccivil_03/_ato2007-2010/2009/lei/112010.htm

Agravo de Instrumento n. 2001.012993-0. (2003). Tribunal de Justiça de Santa Catarina. Relator: Des. Carlos Prudêncio. Laguna. https://tjsc.jusbrasil.com.br/jurisprudencia/5090167/agravo-de-instrumento-ai-129930-sc-2001012993-0

Agravo de Instrumento n. 2002.009848-0. (2002). Tribunal de Justiça de Santa Catarina. Relator: Des. Mazoni Ferreira. Florianópolis. https://tjsc.jusbrasil.com.br/jurisprudencia/5075797/agravo-de-instrumento-ai-98480-sc-2002009848-0

Buosi, C. C. F. (2012). Alienação parental - Uma interface do Direito e da Psicologia. Juruá.

Carvalho, D. M. (2015). Direito das famílias. (4a ed.). Saraiva.

De Plácio e Silva, O. J. (1990). Vocabulário jurídico. (2a ed). Forense.

Diniz, M. H. (2015). Curso de Direito Civil Brasileiro: responsabilidade civil. (29a ed.). Saraiva.

Gagliano, P. S., \& Pamplona, R., Filho. (2016). Novo Curso De Direito Civil: Responsabilidade Civil. (12a ed.). Saraiva.

Gil, A. C. (2008). Como elaborar projetos de pesquisa. (10a ed.). Atlas.

Gonçalves, C. R. (2016). Direito civil brasileiro: direito das coisas. (11a ed.). Saraiva. 
Research, Society and Development, v. 10, n. 14, e418101422268, 2021

(CC BY 4.0) | ISSN 2525-3409 | DOI: http://dx.doi.org/10.33448/rsd-v10i14.22268

Leite, E. O. (2003). Famílias monoparentais: a situação jurídica de pais e mães solteiros, de pais e mães separados e dos filhos na ruptura da vida conjugal. Revista dos Tribunais.

Lôbo, P. L. N. (2011). Código Civil comentado: direito de família, relações deparentesco, direito patrimonial: arts. 1591 a 1693. (v. 16). Atlas.

Machado, M. T. (2003). A proteção constitucional de crianças e adolescentes e os direitos humanos. Manole.

Melo, N. D. (2014). Lições de Direito Civil - Família e Sucessões. (v. 5). Atlas.

Nader, P. (2013). Curso de direito civil: direito de família. (6a ed.). Forense.

Pereira, T. S. (2008). O melhor interesse da criança: um debate interdisciplinar. (2a ed.). Renovar.

Prodanov, C. C., \& FREITAS, E. C. (2013). Metodologia do trabalho científico: métodos e técnicas da pesquisa e do trabalho acadêmico. (2. ed.). Novo Hamburgo: Feevale.

Tartuce, F. (2015). Guarda compartilhada obrigatória. Mito ou realidade? O que muda com a aprovação do PL 117/2013. Jusbrasil. https://flaviotartuce.jusbrasil.com.br/artigos/153734851/guarda-compartilhada-obrigatoria-mito-ou-realidade-o-que-muda-com-a-aprovacao-do-pl-117-2013

Venosa, S. S. (2013). Direito Civil: Direito de Família. (13a ed.). Atlas. 